\title{
Receiver function study of the crustal structure of Northeast China: Seismic evidence for a mantle upwelling beneath the eastern flank of the Songliao Basin and the Changbaishan region*
}

\author{
Huafeng Liu* and Fenglin Niu \\ Department of Earth Science, Rice University, Houston, TX 77005, USA
}

\begin{abstract}
Northeast China is a unique place to study intra-plate volcanism. We analyzed P-wave receiver function data recorded by 111 permanent broadband seismic stations in Northeast China. The results show that the crustal thickness varies from $27.9 \mathrm{~km}$ beneath the eastern flank of the Songliao Basin to $40.7 \mathrm{~km}$ beneath the Great Xing'an Range region. The large depth variations of the Moho can be largely but not completely explained by surface topography. The residual Moho depth calculated based on the Airy's isostasy model indicates that the Moho is dynamically uplifted by $<3 \mathrm{~km}$ beneath the eastern flank of the Songliao Basin and the Changbaishan region. We suggest that a mantle upwelling, which has been proposed by several recent seismic studies, might have caused the uplift.
\end{abstract}

Key words: receiver function; Moho; Northeast China; mantle upwelling CLC number: P315.2 Document code: A

\section{Introduction}

The Northeast China region consists of the Northeast China (NE China) Plain with the Songliao Basin in its center, the Central Asian fold belt, known as the Great Xing'an Range to the west, the uplifted volcanic Changbaishan region to the east and the Sino-Korean Craton to the south. It is located more than $1000 \mathrm{~km}$ away from the Japan Trench, where the Pacific Plate starts to subduct beneath the Eurasia Plate (Figure 1). The region is also located roughly above the so-called stagnant slab where the subducted Pacific slab seems to be deflected sub-horizontally around the $660-\mathrm{km}$ discontinuity (Fukao et al., 2001).

It is widely believed that the Songliao Basin was a rifting basin and the rifting process took place in the Mesozoic (Hu et al., 1998; Ren et al., 2001) immediately after the closure of the Mongol-Okhotsk Ocean. The

\footnotetext{
* Received 22 September 2010; accepted in revised form 21 December 2010; published 10 February 2011.

† Corresponding author. e-mail: hl9@rice.edu

(C) The Seismological Society of China and Springer-Verlag Berlin Heidelberg 2011
}

collision between the Amurian Plate and Siberia block after the closure caused lithospheric thickening of the Great Xing'an Range and NE China, and the later collapse of the thickened lithosphere caused convective thinning of the thermal boundary layer. Late Mesozoic volcanic rocks are widely distributed in the region, indicating that active volcanism occurred during the Mesozoic rifting. Volcanism continued in the Cenozoic time in a rather episodic and sporadic manner (Liu et al., 2001). Although it is generally believed that the Cenozoic volcanism in NE China is somehow related to the subduction of the Pacific Plate beneath the area (e.g., Liu et al., 2001), one obviously cannot invoke a regular back arc volcanogenic model to explain the Cenozoic volcanism in this region.

One promising model, based on tomographic imaging, is the so-called big-mantle-wedge (BMW) model (Lei and Zhao, 2005; Zhao et al., 2009), which hypothesized a large-scale mantle upwelling in this region as the deep origin of the Cenozoic volcanism. Geochemical studies of volatiles and trace elements suggested that the origin of the Changbaishan volcano is within the mantle (Hahm et al. 2008; Kuritani et al., 2009). While 


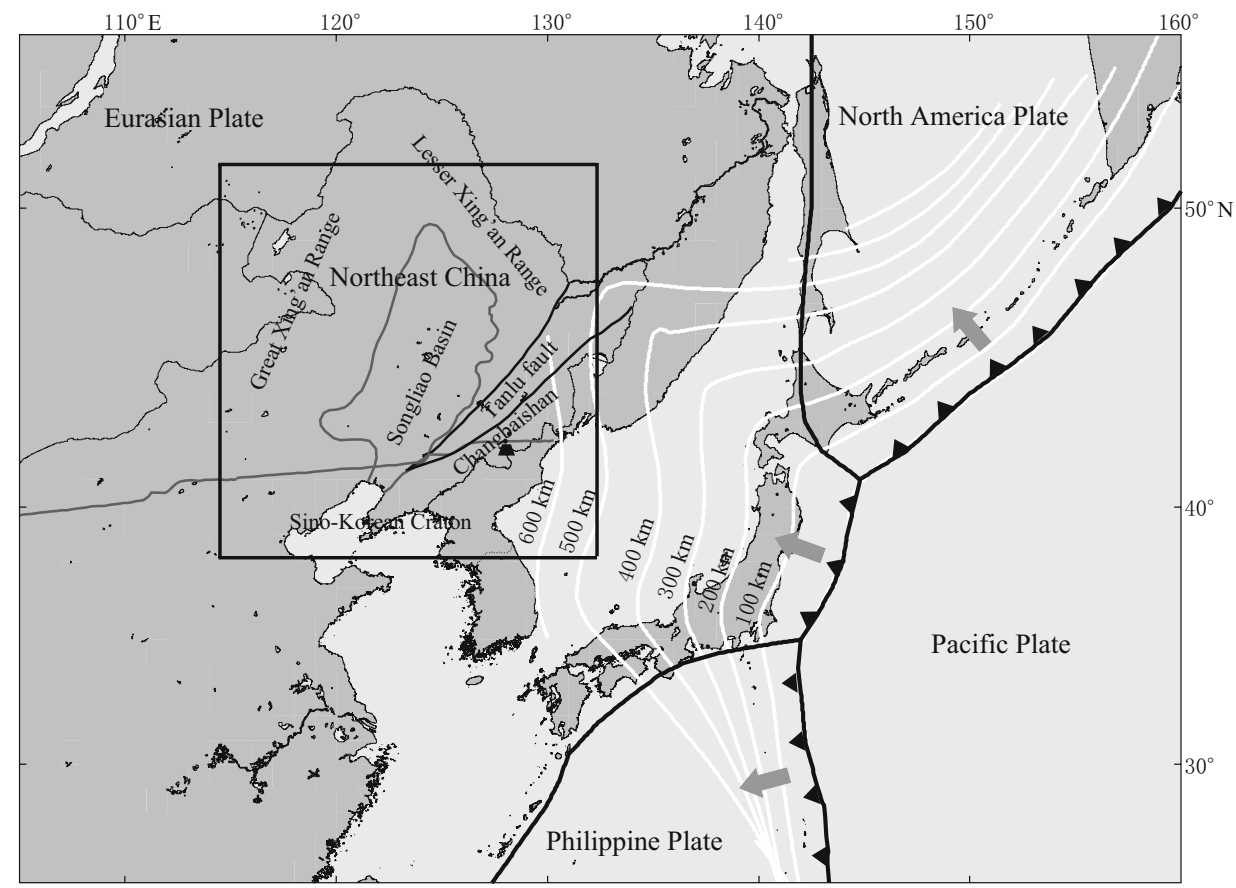

Figure 1 Map showing the major tectonic setting of Northeast China and the surrounding area. The subducting Pacific Plate is shown in white lines, which can be traced to $600 \mathrm{~km}$ deep from seismicity.

there are some geochemical constraints on the presence of an upper mantle upwelling beneath the region (Zou et al., 2008), the depth and lateral distribution remain poorly understood, as does the cause of the upwelling. By combining seismic and electrical conductivity data, Ichiki et al. (2006) proposed two possible mechanisms responsible for the upwelling. Further seismic data are needed to determine which mechanism is more appropriate. Here we investigated the lateral variations of the crust-mantle boundary with receiver-function data to map out possible deformation at the boundary resulting from the upwelling.

\section{CEA regional networks and seis- mic data}

The recent release of broadband waveform data of permanent regional seismic networks in NE China by the China Earthquake Administration (CEA) provided an unprecedented opportunity to investigate the crustal structure of the area (Zheng et al., 2009). There are a total of $128 \mathrm{CEA}$ broadband stations in the study area $\left(115^{\circ} \mathrm{E}-132^{\circ} \mathrm{E}\right.$ and $\left.40^{\circ} \mathrm{N}-52^{\circ} \mathrm{N}\right)$. We collected waveform data from 66 earthquakes with a magnitude $M_{\mathrm{W}} \geq 6.0$ occurred between August 2007 and $\mathrm{Au}-$ gust 2008 recorded at an epicentral distance of $30^{\circ}-90^{\circ}$ (Figure 2a). We visually checked all the seismograms and the receiver function data, and selected a total of
2359 receiver functions with a high signal-to-noise ration (SNR) for further analysis. Among the 128 stations, 111 (Figure $2 \mathrm{~b}$ ) had enough receiver function data to estimate Moho depth and $v_{\mathrm{P}} / v_{\mathrm{S}}$ ratio.

\section{Receiver function analysis}

Early receiver function studies used radial and vertical components to form receiver function. In this case, significant $\mathrm{P}$ wave energy can be seen in receiver functions, which may interfere with the P-to-S converted phase at the Moho and hence affect the measurements. We thus further rotated the vertical and radial components to the $\mathrm{P}$ - and SV-components to avoid the interference and to enhance conversion energy (Niu and Kawakatsu, 1998). We employed the "water-level" deconvolution technique (Clayton and Wiggins, 1976) to generate receiver functions:

$E_{\mathrm{RF}}(\omega)=\frac{V(\omega) P^{*}(\omega)}{\max \left\{P(\omega) P^{*}(\omega), k\left|P_{\max }\left(\omega_{0}\right)\right|^{2}\right\}} \mathrm{e}^{-\left(\frac{\omega}{2 a}\right)^{2}}$.

Here the "water level" parameter $k$ was set to 0.03 to reduce instability of the deconvolution and the Gaussian constant $a$ was set to 1.5 (equivalent to a corner frequency of $0.5 \mathrm{~Hz}$ ) to suppress higher frequencies. $P(\omega)$ and $V(\omega)$ are the spectra of the P-and SV-components computed from a $40 \mathrm{~s}$ time window (5 s before and $35 \mathrm{~s}$ after the first $\mathrm{P}$ arrival). 


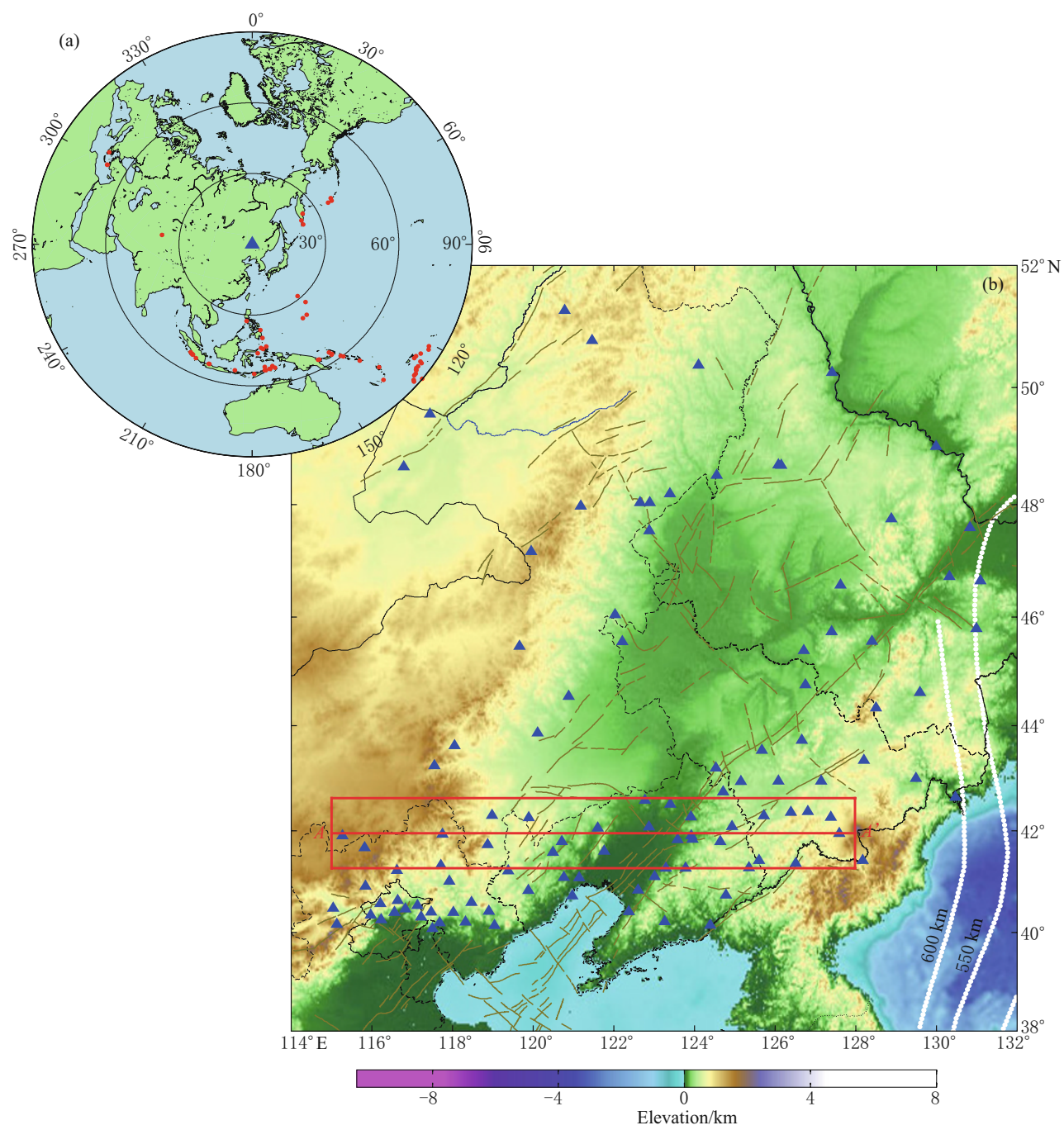

Figure 2 (a) Distribution of the 66 teleseismic events (red dots) used in this study. Most of the earthquakes are located in the south Pacific and Indonesia regions. Note that although some of the events fall into the $30^{\circ}$ circle to the array center, the data we used have an epicentral distance larger than $30^{\circ}$. (b) Geographic map showing the 111 CEA stations from six regional seismic networks of the China Earthquake Administration. White lines indicate the Pacific subducting slab and line $A A^{\prime}$ shows the location of the 2D CCP stacking image shown in Figure 4b. Brown lines indicate faults in the region.

We used a modified $H-\kappa$ stacking method (Zhu and Kanamori, 2000; Niu et al., 2007) to estimate the Moho depth as well as average $v_{\mathrm{P}} / v_{\mathrm{S}}$ ratio within the crust. Following Niu et al. (2007), we refer to the primary P to $\mathrm{S}$ conversion phase as 0P1S, and the two crustal reverberation phases as $1 \mathrm{P} 2 \mathrm{~S}$ and $2 \mathrm{P} 1 \mathrm{~S}$. The numbers before $\mathrm{P}$ and $\mathrm{S}$ indicate the counts of $\mathrm{P}$ - and $\mathrm{S}$-wave legs within the crust, respectively. For each receiver function, we first performed a time to depth conversion by assuming three different modes: the primary $\mathrm{P}$ to $\mathrm{S}$ conversion $0 \mathrm{P} 1 \mathrm{~S}$ mode and the reverberation $1 \mathrm{P} 2 \mathrm{~S}$ and $2 \mathrm{P} 1 \mathrm{~S}$ modes. The time to depth conversion was performed in the range of 0 to $80 \mathrm{~km}$ with an increment of $1 \mathrm{~km}$ using the P-wave velocity model based on local and regional P-wave travel-time data (Sun and Toksöz, 2006) and an assumed $v_{\mathrm{P}} / v_{\mathrm{S}}$ ratio. The ratio was varied from 1.5 to 2.5 with an increment of 0.001 . The three depth traces were then summed with different weights. We further used the cross correlations between the three modes as a weight function and summed the three depth traces:

$$
\begin{gathered}
A(d, r)=\frac{c(r)}{w_{1}+w_{2}+w_{3}}\left[w_{1} A_{0 \mathrm{P} 1 \mathrm{~S}}(d, r)+\right. \\
\left.w_{2} A_{2 \mathrm{P} 1 \mathrm{~S}}(d, r)+w_{3} A_{1 \mathrm{P} 2 \mathrm{~S}}(d, r)\right],
\end{gathered}
$$

where $d$ and $r$ are the Moho depth and $v_{\mathrm{P}} / v_{\mathrm{S}}$ ratio. $w_{1}, w_{2}$, and $w_{3}$ are the weights for $0 \mathrm{P} 1 \mathrm{~S}, 2 \mathrm{P} 1 \mathrm{~S}$ and 
1P2S phase, respectively, and $c(r)$ is the cross correlation weight. Moho depth and $v_{\mathrm{P}} / v_{\mathrm{S}}$ ratio were determined where the summed amplitude reaches its maximum.

For areas with enough station density, we also applied the CCP (common-conversion point) stacking method to image lateral variations of the Moho. To do this, we first ray-traced the IASP91 mode (Kennett and Engdahl, 1991) to compute the P-to-S conversion points at different depths for each source-receiver pair. We then gathered receiver functions sharing conversion points along a 2-D cross section.
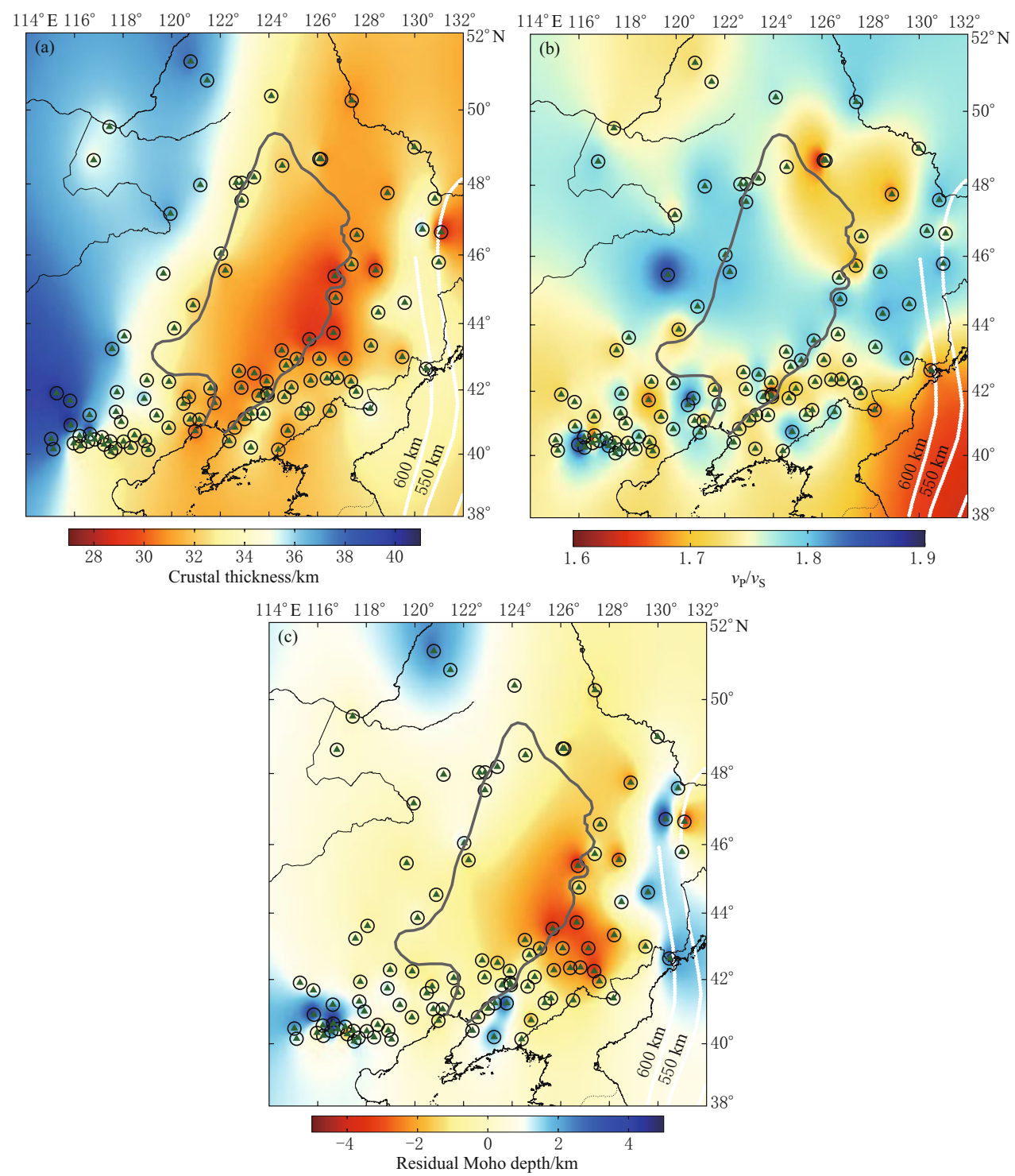

Figure 3 (a) Moho depth map of the study area. The color contour is based on the observations at stations shown as green triangles. Circles roughly represent area sampled by receiver functions, and the crust thickness can be considered as the average over the circles. (b) Map showing the lateral variations of the $v_{\mathrm{P}} / v_{\mathrm{S}}$ ratio. Circles roughly represent area where $v_{\mathrm{P}} / v_{\mathrm{S}}$ ratio is averaged. (c) Map showing the residual Moho depth (see text for detailed calculation). Note a broad uplift with a peak amplitude of $3 \mathrm{~km}$ centered in Changbaishan region.

\section{Results and discussion}

Crust thickness estimated from the $H-\kappa$ stacking is shown in Figure 3a. Average crust thickness is $\sim 29$ $\mathrm{km}$ in the Songliao Basin and increases to $\sim 38 \mathrm{~km}$ in Great Xing'an Range region. The Moho beneath the Great Xing'an Range region west to the basin is deep, while that beneath the Changbaishan region east to the 
basin is a few kilometers shallower. The estimated average crustal $v_{\mathrm{P}} / v_{\mathrm{S}}$ ratio is shown in Figure $3 \mathrm{~b}$. The $v_{\mathrm{P}} / v_{\mathrm{S}}$ ratio varies between 1.6 and 1.9 and generally agrees with geological features of different blocks in the area. The low $v_{\mathrm{P}} / v_{\mathrm{S}}$ ratio in the Changbaishan region is consistent with a previous seismic study of the region (Hetland et al., 2004). Measurement errors of crustal thickness and $v_{\mathrm{P}} / v_{\mathrm{S}}$ ratio are estimated to be $\sim \pm 1 \mathrm{~km}$ and $\sim \pm 0.03$, respectively (Jenkins and Watts, 1968).

To investigate causes of the depth variation of the Moho, we first calculated the predicted depth variation based on surface topography using the Airy model of isostasy that assumes a laterally uniform density within crust and balances the topographically high mountains with a deeply extended crustal roots. We used a constant density of $2.8 \times 10^{3} \mathrm{~kg} \cdot \mathrm{m}^{-3}$ and $3.3 \times 10^{3} \mathrm{~kg} \cdot \mathrm{m}^{-3}$ for the crust and upper mantle, respectively. We further removed the mean value to show lateral variations at Moho depth. The main feature shown in the residual Moho depth map is a broad negative anomaly along the eastern flank of the Songliao Basin and the Changbaishan region (Figure 3c). The negative anomaly has a $\sim 3 \mathrm{~km}$ peak amplitude centered roughly at the Changbaishan volcano and extends $\sim 300 \mathrm{~km}$ and $\sim 400 \mathrm{~km}$ in the EW and NS directions, respectively.

To further illustrate the significant difference observed at Moho depth between the western and eastern edge of the Songliao Basin, we made a 2D CCP image along an EW line at $42^{\circ} \mathrm{N}$ (Figure 2b), where we have high enough station density. The CCP stacked image (Figure $4 \mathrm{~b}$ ) shows a clear Moho, which is $\sim 40 \mathrm{~km}$ in the west, $\sim 30 \mathrm{~km}$ beneath the southern margin of the Songliao Basin, and $\sim 33 \mathrm{~km}$ in the east. The deep-shallow-intermediate Moho pattern generally corresponds to the high-low-intermediate pattern of average topography (Figure 4a). However, a careful comparison between the two indicates that the eastern side of the basin has a significantly shallower root than the western one although both rise to a roughly similar altitude (from $0.4 \mathrm{~km}$ to $1.2 \mathrm{~km}$ ).

A negative anomaly corresponds to a relatively shallower Moho compared to the Airy's static prediction. Since this anomaly roughly coincides with the region with a low velocity in the upper mantle, we assume that the uplift seen here reflects the dynamic deformation related to the low velocity anomaly (Lei and Zhao, 2005; Zhao et al., 2009). Lei and Zhao (2005) attributed the low velocity anomaly to dehydration from the sub-horizontally deflected slab. On the other hand, the lateral resolution of the tomographic images is of either local or global scale. Thus it is hard to identify a vertically consistent anomaly from these images. The Moho uplifted region is located $\sim 200-500 \mathrm{~km}$ west to the $600 \mathrm{~km}$ contour of the observed deep seismicity in the area (Figure 3c). We thus speculated that this broad uplift is somehow associated with the presence of deep subduction in this region.
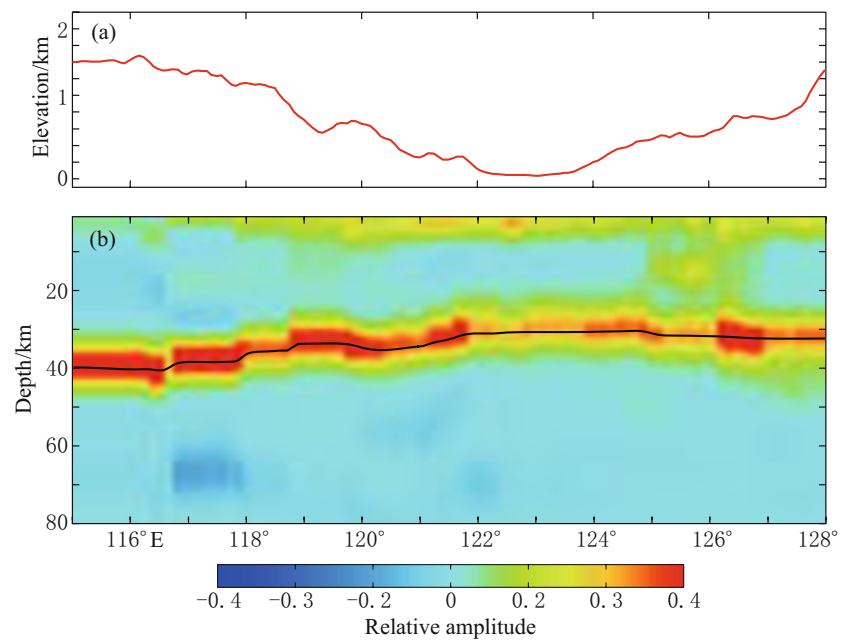

Figure 4 Elevation (a) and CCP image (b) along line $A A^{\prime}$ at $42^{\circ} \mathrm{N}$ shown in Figure 2. $\mathrm{P}$ to $\mathrm{S}$ converted energy is indicated by colors; hotter colors represent greater energy. Note that the Moho is clearly imaged (black line). No significant deepening of Moho was observed beneath the Changbaishan region located at the eastern end of the profile.

While both thermal and compositional buoyancy have been proposed to be the driving force of the upwelling (Ichiki et al., 2006), here we assume the observed deformation at the Moho has a thermal origin. The thermal buoyancy force, $\Delta F_{\mathrm{b}}$, due to a temperature anomaly, $\Delta T$, supports the mass contrast, $\Delta W$, between mantle and crustal material filled within the uplift Moho space (Figure 5):

$$
\left(\rho_{\mathrm{M}}^{\prime}-\rho_{\mathrm{M}}\right) g h=\left(\rho_{\mathrm{M}}-\rho_{\mathrm{C}}\right) g \Delta h,
$$

here $\rho_{\mathrm{C}}$ and $\rho_{\mathrm{M}}$ are the average densities of the crust and the upper mantle, respectively. $h$ and $\Delta h$ are the height of the temperature anomaly body and the amount of uplift of the crust-mantle boundary, respectively. $\rho_{\mathrm{M}}^{\prime}$ is the mantle density with an elevated temperature $(\Delta T)$, which can be calculated from the thermal expansion coefficient, $\alpha$,

$$
\frac{\rho_{\mathrm{M}}^{\prime}-\rho_{\mathrm{M}}}{\rho_{\mathrm{M}}}=-\alpha \Delta T .
$$




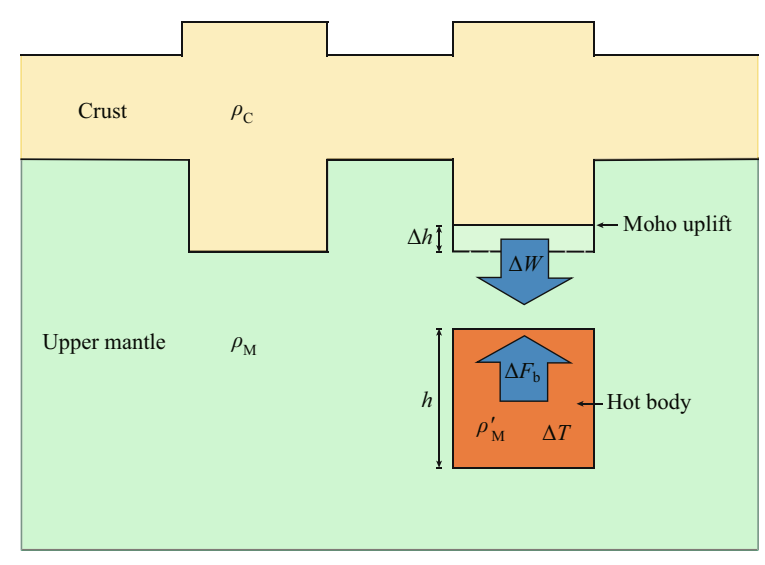

Figure 5 A schematic model showing the balance between the buoyancy $\left(\Delta F_{\mathrm{b}}\right)$ caused by a hot upwelling shown in orange and the extra mass $(\Delta W)$ due to a reduced crustal root.
From equations (3) and (4), we obtain

$$
\Delta T \cdot h=\frac{\left(\rho_{\mathrm{M}}-\rho_{\mathrm{C}}\right) \Delta h}{\alpha \rho_{\mathrm{M}}} .
$$

Taking typical values of density and the thermal expansion coefficient of the crust and the mantle: $\rho_{\mathrm{C}}=$ $2.8 \times 10^{3}\left(\mathrm{~kg} \cdot \mathrm{m}^{-3}\right), \rho_{\mathrm{M}}=3.3 \times 10^{3}\left(\mathrm{~kg} \cdot \mathrm{m}^{-3}\right)$ and $\alpha=$ $3 \times 10^{-5}\left(K^{-1}\right)$, a $\Delta h$ of $3 \mathrm{~km}$ would result in a $\Delta T \cdot h=1.5 \times 10^{7}(\mathrm{~m} \cdot \mathrm{K})$. If we assume $\Delta T=150 \mathrm{~K}$, as suggested by Ichiki et al. (2006), the depth extension of the thermal upwelling is estimated to be $\sim 100 \mathrm{~km}$, which is consistent with the estimate of Ichiki et al. (2006).

In Figure 6, we show a 3-D perspective view of the broad uplift observed at the Moho and surface topography. We also show a schematic upwelling at around $\sim 150 \mathrm{~km}$ with a depth extension of $100 \mathrm{~km}$. Further

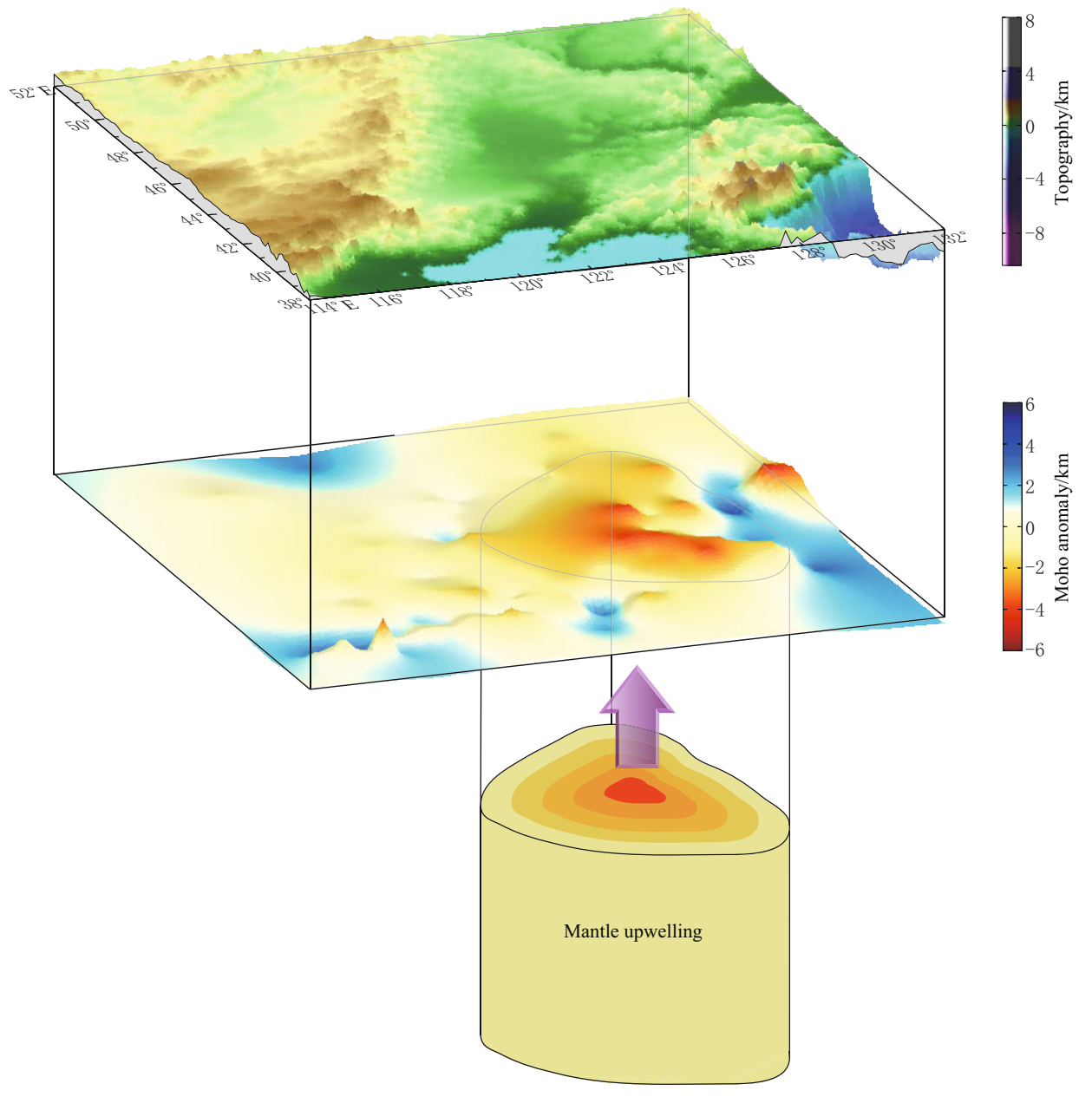

Figure 6 Map showing a 3D perspective view of the broad Moho uplift and the topography relief of the study area. A mantle upwelling is schematically shown beneath the Changbaishan area to indicate the dynamic origin of the observed deformation of the Moho. 
detailed modeling is required to constrain the lateral scale as well as the absolute depth of the anomaly.

\section{Conclusions}

We investigated crustal structure in the Northeast China region using receiver function data recorded by several regional seismic networks in the region. We found: (1) the Songliao Basin has a relatively thin crust, probably resulting from rifting that occurred in the Mesozoic; (2) high topography of the Great Xing'an Range located at the western boundary of the basin is almost isostatically balanced by a thick crustal root; (3) the eastern margin of the Songliao Basin, where active Cenozoic volcanism occurred, is underlain by a relative thin crust, despite the relatively high topography in these regions, consistent with the presence of a mantle upwelling proposed by previous studies. Our observations suggested that variations in crustal thickness seem to play an important role in determining tectonic activity in the study region.

Acknowledgements We thank the Data Management Center of the China Earthquake Administration for providing the data. We thank Jennifer Mackenzie for revising this paper. This work is supported by NSF grant EAR-063566.

\section{References}

Clayton R W and Wiggins R A (1976). Source shape estimation and deconvolution of teleseismic bodywaves. Geophys $J$ R astr Soc 47(1): 151-177.

Fukao Y, Widiyantoro S and Obayashi M (2001). Stagnant slabs in the upper and lower mantle transition region. Rev Geophys 39: 291-323.

Hahm D, Hilton D R, Cho M, Wei H and Kim K R (2008). Geothermal $\mathrm{He}$ and $\mathrm{CO}_{2}$ variations at Changbaishan intra-plate volcano (NE China) and the nature of the sub-continental lithospheric mantle. Geophys Res Lett 33: L12304, doi:10.1029/2008GL035955.

Hetland E A, Wu F T and Song J L (2004). Crustal structure in the Changbaishan volcanic area, China, determined by modeling receiver functions. Tectonophysics 386: $157-175$.

Hu W S, Cai C F, Wu Z Y and Li J M (1998). Structural style and its relation to hydrocarbon exploration in the Songliao Basin, northeast China. 15: 41-55.

Ichiki M, Baba K, Obayashi M and Utada H (2006). Water content and geotherm in the upper mantle above the stagnant slab: Interpretation of electrical conductivity and seismic P-wave velocity models. Phys Earth Planet Inter 155: 1-15.

Jenkins G M and Watts D G (1968). Spectral Analysis and Its Applications. Holden-Day, San Francisco, Calif., 525pp.

Kennett B L N and Engdahl E R (1991). Traveltimes for global earthquake location and phase identification. Geophys J Int 105: 429-465, doi:10.1111/j.1365246X.1991.tb06724.x.

Lei J S and Zhao D P (2005). P-wave tomography and origin of the Changbai intraplate volcano in Northeast Asia. Tectonophysics 397: 281-295.

Liu J Q, Han J T and Fyfe W S (2001). Cenozoic episodic volcanism and continental rifting in northeast China and possible link to Japan Sea development as revealed from K-Ar geochronology. Tectonophysics 339: 385-401.

Niu F and Kawakatsu H (1998). Determination of the absolute depths of the mantle transition zone discontinuities beneath China: Effect of stagnant slabs on transition zone discontinuities. Earth Planets Space 50(11-12): 965-975.

Niu F, Bravo T, Pavlis G, Vernon F, Rendon H, Bezada $\mathrm{M}$ and Levander A (2007). Receiver function study of the crustal structure of the southeastern Caribbean plate boundary and Venezuela. J Geophys Res 112: B11308, doi:10.1029/2006JB004802.

Kuritani T, Kimara J, Miyamoto T, Wei H Q, Shimano T, Maeno F, Jin X and Taniguchi H (2009). Intraplate magmatism related to deceleration of upwelling asthenospheric mantle: Implications from the Changbaishan shield basalts, Northeast China. Lithos 112: 247258.

Ren J Y, Tanaki K, Li S T and Zhang J X (2001). Late Mesozoic and Cenozoic rifting and its dynamic setting in Eastern China and adjacent areas. Tectonophysics 344: 175-205.

Sun Y and Toksöz M N (2006). Crustal structure of China and surrounding regions from $\mathrm{P}$ wave traveltime tomography. J Geophys Res 111: B03310, doi: 10.1029/2005JB003962.

Zhao D P, Tian Y, Lei J S, Liu L and Zheng S H (2009). Seismic image and origin of the Changbai intraplate volcano in East Asia: Role of big mantle wedge above the stagnant Pacific slab. Phys Earth Planet Inter 173: 197206.

Zheng X F, Ouyang B, Zhang D N, Yao Z X, Liang J H and Zheng J. (2009). Technical system construction of Data Backup Centre for China Seismograph Network and the data support to researches on the Wenchuan earthquake. Chinese J Geophys 52(5): 1412-1 417, doi:10.3969/j.issn.0001-5733.2009.05.031 (in Chinese with English abstract).

Zhu L P and Kanamori H (2000). Moho depth variation in southern California from teleseismic receiver functions. $J$ Geophys Res 105(B2): 2 969-2 980.

Zou H B, Fan Q C and Yao Y P (2008). U-Th systematics of dispersed young volcanoes in NE China: Asthenosphereupwelling caused by piling up and upward thickening of stagnant Pacific slab. Chemical Geology 255: 134-142. 